\title{
TÄRKEIMPIEN PELTOKASVIEN HEHTAARISATOJEN KEHITYS SUOMESSA
}

\author{
LEO YLLÖ \\ Maatalouden tutkimuskeskus, Kasvinviljelylaitos, Tikkurila
}

Saapunut 21. 4. 1961

Seuraavassa tarkastellaan syysrukiin, kevätvehnän, ohran, kauran, perunan ja peltoheinän hehtaarisatojen kehitystä Suomessa v. 1921-60. Kun mainittujen kasvien viljelyssä oli suurin osa maan peltoalasta, esimerkiksi v. $1951-60$ yhteensä $81 \%$, antaa selvitys samalla kuvan kasvinviljelyssä tapahtuneista satotason muutokssista yleensä.

\section{Aineisto ja käsittelytapa}

Hehtaarisatojen muutosten tarkastelu perustuu Suomen viralliseen tilastoon (6). Laskutyön yksinkertaistamiseksi tilastossa esiintyvät hehtaarisadot pyöristettiin kymmenen kilon tarkkuuteen. Tämä aineisto koottiin, ryhmiteltynä kymmenvuosiluvuttain, taulukkoon 1 . Vuosivaihtelujen voimakkuuden osoittamiseksi laskettiin satovaihtelukertoimet (hajonta \%:na keskisadosta). Satotason muutokset on esitetty myös piirroksessa 1 seuraavasti: 1) vuosittaiset ha-sadot, 2) viiden vuoden ha-satojen liukuvat keskiarvot ja 3) trendi eli pääsuunta. Trendi laskettiin pienimmän neliösumman menetelmällä käyttäen ensimmäisen asteen regressioyhtälöä $\mathrm{y}=\mathrm{a}+\mathrm{b} . \mathrm{x}$ ja normaaliyhtälöitä $\Sigma \mathrm{y}=$ n.a sekä $\Sigma \mathrm{x} \cdot \mathrm{y}=\mathrm{b} . \Sigma \mathrm{x}^{2}$. Tulosten luotettavuus tarkasteltiin t-testillä $(2,4)$.

\section{Hehtaarisatojen kehitys}

Maataloudessa tapahtuneen kehityksen ansiosta ovat hehtaarisadot neljän viimeisen vuosikymmenen aikana melkoisesti kohonneet. Kehitys on ollut kuitenkin varsin epätasaista. Huomio kiintyy suuriin vuosivaihteluihin, jøita on esiintynyt kaikkina vuosikymmeninä (piirros 1). Nämä, lähinnä sääoloista johtuvat muutokset olivat suuria varsinkin 1940-luvulla, jolloin sota- ja säännöstelyvuodet lisäsivät satovaihtelua. Niinpä satovaihtelukertoimet olivatkin 1940-luvulla suuria $(13-21 \%)$, kun ne sitä vastoin muina vuosikymmeninä jäivät useimmilla kasveilla 
selvästi pienemmiksi. Huomioon ottaen vuodet $1921-60$, vaihtelukertoimet olivat myös suuria, 13-22\%, mikä johtuu siitä, että epäsäännöllisten vaihtelujen lisäksi niihin sisältyy myös trendista johtuva muuntelu. Sy y ruki in satovaihtelukerroin oli pienin (13\%), johon osaltaan vaikuttivat 1950-luvun suhteellisen tasaiset sadot. Tämän lisäksi on rukiin satovaihteluja ilmeisesti tasoittanut se, että huonosti talvehtineita laihoja on keväisin kynnetty nurin. K e vä t v e h $n$ ä $n$ vaihtelukerroin $(15 \%)$ oli hieman suurempi kuin rukiin, mutta pienempi kuin o h r a n $(18 \%)$ ja k a u r a n $(19 \%)$. Ohran ja kauran huonompi viljelyvarmuus kevätveh-

Taulukko 1. Tärkeimpien peltokasvien ha-sadot ja satovaihtelukertoimet Suomessa v. $1921-60$.

Tabelle 1. Die Hektarerträge der wichtigsten Ackerpflanzen und ihre Variationskoeffizienten in Finnland in den Jahren 1921-60.

\begin{tabular}{|c|c|c|c|c|c|c|c|c|c|c|c|c|}
\hline \multirow{2}{*}{$\begin{array}{l}\text { Vuodet } \\
\text { Jahre }\end{array}$} & \multicolumn{2}{|c|}{$\begin{array}{l}\text { Syysruis } \\
\text { Winter- } \\
\text { roggen }\end{array}$} & \multicolumn{2}{|c|}{$\begin{array}{c}\text { Kevätvehnä } \\
\text { Sommer- } \\
\text { weizen }\end{array}$} & \multicolumn{2}{|c|}{$\begin{array}{l}\text { Ohra } \\
\text { Gerste }\end{array}$} & \multicolumn{2}{|c|}{$\begin{array}{l}\text { Kaura } \\
\text { Hafer }\end{array}$} & \multicolumn{2}{|c|}{$\begin{array}{c}\text { Peruna } \\
\text { Kartoffeln }\end{array}$} & \multicolumn{2}{|c|}{$\begin{array}{c}\text { Peltoheinä } \\
\text { Kleegras- } \\
\text { heu }\end{array}$} \\
\hline & $\mathrm{kg} / \mathrm{ha}$ & $\mathrm{s} \%$ & kg/ha & $\mathbf{s} \%$ & $\mathrm{~kg} / \mathrm{ha}$ & $\mathbf{s} \%$ & $\mathrm{~kg} / \mathrm{ha}$ & $\mathbf{s} \%$ & $\mathrm{~kg} / \mathrm{ha}$ & $\mathbf{s} \%$ & $\mathrm{~kg} / \mathrm{ha}$ & $\mathbf{s} \%$ \\
\hline $1921-30$ & 1310 & 12 & 1380 & 12 & 1220 & 15 & 1250 & 13 & 10030 & 19 & 2740 & 11 \\
\hline $1931-4 \theta$ & 1490 & 12 & 1630 & 10 & 1450 & 10 & 1500 & 12 & 14740 & 9 & 2860 & 17 \\
\hline $1941-50$ & 1250 & 13 & 1340 & 14 & 1270 & 17 & 1330 & 17 & 13060 & 21 & 2400 & 17 \\
\hline $1951-60$ & 1480 & 7 & 1610 & 14 & 1650 & 13 & 1690 & 15 & 14940 & 17 & 3010 & 6 \\
\hline $1921-60$ & 1380 & 13 & 1490 & 15 & 1400 & 18 & 1440 & 19 & 13190 & 22 & 2750 & 15 \\
\hline
\end{tabular}

nään verrattuna johtuu lähinnä siitä, että ohraa ja kauraa viljellään suhteellisen runsaasti myös Pohjois-Suomessa, jossa kevätviljojen satovaihtelut ovat suurempia kuin etelässä (5). Kauraa viljellään sitä paitsi yleisesti suomailla, joilla hallaisuus lisää satovaihtelua. P e r u n a n satovaihtelut olivat suurimpia, vaihtelukerroin $22 \%$. Vain 1930-luvulla saatiin perunastakin suhteellisen tasaisia satoja. P e 1 t o$\mathrm{h}$ e i $\mathrm{n}$ ä $\mathrm{n}$ hehtaarisatojen vaihtelut poikkeavat muista sikäli, että ne olivat suuria jo 1930-luvulla, johon lähinnä vaikutti satojen jyrkkä lasku v. 1939—40. Kaikki neljä vuosikymmentä huomioon ottaen peltoheinän vaihtelukerroin oli $15 \%$.

Satotason muutokset selviävät havainnollisimmin liukuvien keskisatojen käyristä (piirros 1). Yleispiirteenä mainittakoon, että eri kasvien satokäyrät ovat sangen samankaltaisia. Tämä koskee varsinkin viljakasveja, jotka myös satotasoon nähden ovat parhaiten toisiinsa verrattavissa. Piirroksesta havaitaan, että viljakasvien ja perunan satotaso kohosi varsin tasaisesti 1930-luvun puoliväliin saakka. Peltoheinän sadot olivat suhteellisen hyviä jo 1920-luvulla. Edellämainittu suotuisa kehitys kääntyi sotavuosina jyrkkään laskuun, mikä jatkui, lukuunottamatta peltoheinää, 1940-luvun puoliväliin saakka. Viljakasvien sadot alenivat tällöin suunnilleen 1920luvun tasolle, peltoheinän sato sitä vieläkin alemmaksi ja vain perunan sadot pysyivät hieman parempina. Laskukauden jälkeen kuitenkin kaikkien kasvien sadot suurenivat varsin nopeasti niin, että vuosikymmenen vaihteessa satotaso oli $\mathrm{r}$ u k i i 1 l a ja h e in ä 11 ä joksenkin sama kuin 1930-luvun parhaina vuosina, o h r a n ja k a u ran satotaso jopa sitä parempi, mutta kevätvehnän ja perunan 


huonompi. Satotason edullinen kehitys pysähtyi 1950-luvulla. Vuoden 1960 sadot olivat kuitenkin poikkeuksellisen hyviä. Tärkeimpänä syynä siihen, etteivät sadot viljelyn voimaperäistyttämisestä huolimatta 1950-luvulla kohonneet, olivat epäedulliset sääolot $(3,7,8)$.

Satotason kehityksen pääsuunta oli kaikilla kasveilla nouseva (piirros 1). Kuten trendilasku osoitti, oli sadonlisäys suurin perunalla eli keskimäärin $1.1 \%$ vuodessa, laskettuna vuosien 1921-60 keskisadosta (taul. 2). Kauran ja ohran sadot kohosivat hieman hitaammin $(0.8 \%)$, kun sitä vastoin heinän, rukiin ja kevätvehnän sadonlisäys oli vain $0.2-0.4 \%$. Rukiin ja kevätvehnän kohdalla lisäys ei ollut tilastollisesti varma (P-arvo rukiilla $20 \%$, kevätvehnällä $8 \%$ ). Tällä tavoin laskettu satotason paraneminen oli siis varsin vaatimaton, mikä on selitettävissä lähinnä 1940luvun satojen laskulla. Mainitun laskukauden jälkeen sadot paranivat kuitenkin

Taulukko 2. Tärkeimpien peltokasvien ha-sadot (a) ja keskimääräinen sadonlisäys vuodessa (b) Suomessa vuosina $1921-60$ ja $1946-60$.

Tabelle 2. Die Hektarerträge der wichtigsten Ackerpflanzen (a) und ihre mittlere jährliche Steigerung (b) in Finnland in den Jahren 1921-60 und 1946-60.

\begin{tabular}{|c|c|c|c|c|c|c|}
\hline & $\begin{array}{l}\text { Syysruis } \\
\text { interroggen }\end{array}$ & $\begin{array}{l}\text { Kevätvehnä } \\
\text { Sommerweizen }\end{array}$ & $\begin{array}{l}\text { Ohra } \\
\text { Gerste }\end{array}$ & $\begin{array}{l}\text { Kaura } \\
\text { Hafer }\end{array}$ & $\begin{array}{c}\text { Peruna } \\
\text { Kartoffeln }\end{array}$ & $\begin{array}{l}\text { Peltoheinä } \\
\text { Kleegrasheu }\end{array}$ \\
\hline \multicolumn{7}{|c|}{$1921-60$} \\
\hline $\mathrm{a}-\mathrm{kg} / \mathrm{ha}$ & 1380 & 1490 & 1400 & 1440 & 13190 & 2750 \\
\hline $\mathrm{b}-\mathrm{kg} / \mathrm{ha}$ & $3.6 \pm 3.0$ & $5.3 \pm 3.0$ & $11.3 \pm 2.9^{* * *}$ & $11.9 \pm 3.2^{* * *}$ & $140.8 \pm 31.7 * * *$ & $5.7 \pm 1.8 * *$ \\
\hline $\mathrm{b}-\%$ & 0.3 & 0.4 & 0.8 & 0.8 & 1.1 & 0.2 \\
\hline \multicolumn{7}{|c|}{$1946-60$} \\
\hline $\mathrm{a}-\mathrm{kg} / \mathrm{ha}$ & 1430 & 1540 & 1550 & 1600 & 14610 & 2860 \\
\hline$b-\mathrm{kg} / \mathrm{ha}$ & $19.0 \pm 9.2$ & $36.4 \pm 8.0^{* * *}$ & $34.2 \pm 1.2^{* * *}$ & $37.2 \pm 6.7 * * *$ & $189.7 \pm 30.1 * * *$ & $58.2 \pm 16.1^{* *}$ \\
\hline $\mathbf{b}-\%$ & 1.3 & 2.4 & 2.5 & 3.7 & $1 . \overline{3}$ & 2.0 \\
\hline
\end{tabular}

nopeasti, kuten jo edellä todettiin. Jos lähtökohdaksi otetaan vuosi 1946 , jolloin rukiin, kevätvehnän ja kauran hehtaarisadot olivat alimmillaan ja muittenkin kasvien sadot heikkoja, oli sadonlisäys v. 1946 - 60 varsin huomattava eli eri kasveilla $1.3-3.7 \%$. Suhteellisen eniten oli noussut $\mathrm{k}$ a u $\mathrm{r}$ a $\mathrm{n}$ ja vähiten $\mathrm{p}$ e $\mathrm{r}$ u $\mathrm{n}$ a $\mathrm{n}$ ja $\mathrm{r}$ u k i i n sato. Rukiin sadonlisäys ei ollut tilastollisesti varma $(\mathrm{P}=6 \%)$, mikä johtuu lähinnä siitä, ettei satotason kehitys ollut riittävän suoraviivaista. Vertailun vuoksi mainittakoon, että aikaisemmin suoritetun tutkimuksen mukaan oli tarkastelun kohteena olevien kasvien sadonnousu Suomessa v. 1920 - 34 1.3 - 4.5\% (1). Hehtaarisadot suurenivat silloin yhtä pitkän ajanjakson (15 v.) aikana suhteellisesti suunnilleen yhtä paljon kuin v. 1946-60.

Piirros 1. Tärkeimpien peltokasvien ha-sadot Suomessa v. 1921-60. Katkonnainen viiva - sadot eri vuosina, pisteviiva - viiden vuoden liukuvat keskisadot, suora viiva - trendi.

Abb. 1. Die Hektarerträge der wichtigsten Ackerpflanzen in Finnland in den Jahren 1921-60. Gestrichelte Linie - die Erträge der einzelnen Jahre, punktierte Kurve - die fünfjährige gleitende Durchschnitte, ausgezogene Gerade - Trend. 


$$
\text { Ti } i \text { vistel } m \ddot{a}
$$

Edellä tarkasteltiin tärkeimpien peltokasvien satotason kehitystä Suomessa v. $1921-1960$.

Hehtaarisatojen muutoksille olivat epäsäännölliset, lähinnä sääoloista johtuvat vuosivaihtelut luonteenomaisia. Eri kasvien satovaihtelu oli, ilmaistuna vaihtelukertoimella, $13-21 \%$. Satovaihtelu oli suurin perunalla ja pienin syysrukiilla.

Satotason kehitys oli eri kasveilla pääpiirteissään sama. Hehtaarisadot kohosivat 1920- ja 1930-luvulla varsin tasaisesti, mutta laskivat sotavuosina. Alimmilleen satotaso laski 1940-luvun puolivälissä, peltoheinällä jo aikaisemmin. Laskukautta seurasi satojen jyrkkä nousu, joka palautti tason suunnilleen sotia edeltäneelle suhteellisen korkealle tasolle.

Hehtaarisatojen kehityksen pääsuunta on ollut nouseva. Keskimääräinen sadonlisäys oli, huomioon ottaen vuodet $1921-60$ sangen pieni, $0.2-1.1 \%$ vuodessa. Pääasiallisena syynä tähän oli satojen lasku sota- ja säännöstelyvuosina. Huomattavasti suurempi, keskimäärin $1.3-3.7 \%$, oli lisäys laskukauden jälkeen vuosina 1946-60. Sadon nousu oli suurin kauralla ja pienin syysrukiilla ja perunalla.

\section{KIRJALLISUUTTA}

(1) JĀrvesoo, E. 1936. Meie pôllukultuuride hektaari-saakide tõus 1920.-1936. a. Agronoomia 16: $651-654$.

(2) Matrila, S. 1958. Tilastotiede. Kauppakorkeakoulun moniste. $149 \mathrm{~s}$. Hki.

(3) Pantela, J. 1958. Varför stiger inte hektarskördarna? Nord. Jordbrugsforskn. 40: 95-104

(4) Snedecor, G. W. 1950. Statistical Methods. 485 p. Ames, Iowa.

(5) Suomela, H. \& Pantela, J. 1961. Peltokasvien hehtaarisatojen vaihtelu eri maanviljelyseurojen alueilla v. 1948-1957. Maatal. ja koetoim. 15: 56-65.

(6) Suomen virallinen tilasto III: 18-III: 53, (1921-1960).

(7) Valle, O. 1957. Die Entwicklung des finnischen Pflanzenbaus nach dem zweiten Weltkrieg. Maatal. tiet. aikak. 29:167-176.

(8) _- 1958. Sääolot ja niiden vaikutus kasvituotantoon Etelä-Suomessa 1946-57. Maatal. ja koetoim. 12:18-1961.

\section{REFERAT:}

DIE ENTWICKLUNG DER HEKTARERTRÄGE DER WICHTIGSTEN ACKERPFLANZEN IN FINNLAND

LEO YLLÖ

Abteilung für Pflanzenbau, Zentrale für Landwirtschaftliche Forschung. Tikkurila

Die vorliegende, auf Grund der offiziellen Statistik zusammengefasste Ubersicht hat gezeigt, dass die Erträge der wichtigsten Ackerpflanzen Finnlands (Winterroggen, Sommerweizen, Gerste, Hafer, Kartoffeln und Kleegras mit einer Gesamtanbaufläche von ca. $80 \%$ der Ackerfläche) deutlichen Schwankungen unterstehen (vgl. Abb. 1). Die Variationskoeffizienten (die Streuung in \% vom mittleren Ertrag) betrugen in den Jahren 1921-60. bei den obengenannten Kulturen 13-22\% (Tab. 1). Die grosse Variabilität ist hauptsächlich auf den unregelmässigen und öfters ungünstigen Verlauf der Witterungsverhältnisse zurückzuführen. 
Die Entwicklung des Ertragsniveaus ist in Abb. 1 durch die fünfgliedrigen gleitenden Durchschnittserträge veranschaunlicht. Daraus ist zu ersehen, dass die Entwicklung bis Ende der Dreissigerjahre günstig verlief. Die Kriegs- und Nachkriegsjahre zeigten einen beträchtlichen Rückgang während der ersten Hälfte der Vierzigerjahre. Der Tiefstand wurde jedoch verhältnismässig schnell überwunden, so dass das Niveau der Vorkriegszeit bald erreicht wurde. Während der Fünfzigerjahre hat die günstige Entwicklung sich trotz mancher Fortschritte in der Landwirtschaft verlangsamt, woran hauptsächlich die ungünstige Witterung schuld ist.

Um die Hauptrichtung der Entwicklung festzustellen, ist der Trend nach dem Verfahren der kleinsten Quadratsummen berechnet worden. Die auf diese Weise erhaltene jährliche Steigerung betrug in den Jahren 1921-60 im Mittel 0.3-1.1\% (Tab. 2). Der Aufstieg der Erträge war demnach ziemlich schwach, was vor allem auf den störenden Einfluss der Kriegsjahre zurückzuführen ist. Für die letzten fünfzehn Jahre ist dagegen eine beteutend intensivere Steigerung festzustellen, und zwar 1.3-3.7\% von dem mittleren Ertrag je Jahr. Der Aufstieg war bei Hafer und bei Gerste am deutlichsten; die Ertragskurven der verschiedenen Pflanzen weisen jedoch in ihrem Verlauf im allgemeinen merkliche Åhnlichkeiten auf. Zum Schluss sei erwähnt, dass bei Beurteilung der Hektarerträge Finnlands die geographische Lage des Landes berücksichtigt werden muss. Der Getreidebau z.B. erreicht hier seine nördlichste Grenze. 